\title{
Tomato fruit quality and processing ability are impacted by irrigation regime as well as genotype and maturity stage.
}

Alexandre Arbex de Castro Vilas Boas ${ }^{1}$, David Page ${ }^{2}$, Robert Giovinazzo ${ }^{3}$, Nadia Bertin ${ }^{1}$ and AnneLaure Fanciullino ${ }^{1}$

1UR 1115 Plantes et Systèmes de cultures Horticoles, Institut National de la Recherche Agronomique, Centre PACA, Avignon, France 2UMR 408 Sécurité et Qualité des Produits d'Origine Végétale, INRA, Centre PACA, Université d'Avignon, Avignon, France

${ }^{3}$ Société Nationale Interprofessionnelle de la Tomate, Avignon, France

\section{Abstract}

In order to investigate how pre-harvest conditions impact fresh fruit quality, and especially their quality attributes related to industry use, we identified and quantified fresh fruit traits which are impacted by low water supply and their consequences on puree quality, with a focus on viscosity, sugar/acid balance and carotenoid content. A first trial in 2016, indicated that lowering water supply to $50 \%$ of the evapotranspiration (ETP) all along the fruit development impacted plants without significantly affect yields, but impacted the fruit reactivity to the process. To confirm these results, and seek for the limits of reducing water supply, the same experimentation was design except that a more severe water deficit was applied. Control plants were irrigated in order to match $100 \%$ of the (ETP). Water deficit (WD) plants were irrigated as control plants was until anthesis of the first flowers, and then, the irrigation was reduced to $50 \%$ of the ETP. The results obtained in 2017 were compared to those obtained in 2016 on the basis of same variables. Soil humidity, leaf conductance, leaf and fruit water potential and fruit growth were monitored revealing interactive effects between crop and process management. It pointed out links between fresh fruit characteristics and puree quality, depending on genotype and watering regime. As in 2016, WD hardly reduced yield, but increased dry matter content. The puree viscosity strongly depended on the genotype, and the viscosity was disconnected from the soluble solid content (brix). The fruits enzymatic reactivity, estimated through the difference of viscosity measured between hot-break and coldbreak purees were reduced dramatically under WD for all the genotypes. This work opens new perspectives for managing puree quality in the field and for reducing water use in the pre-harvest period and energy cost during processing.

Keywords:Quality, Solanum lycopersicum, deficit irrigation, pre- and post-harvest links, antioxidants, thermal processing, consistency

\section{INTRODUCTION}

Processing tomato is a major crop that represents the principal source of important phytonutrients such as $\beta$-carotene and lycopene (Dorais, Ehret et al. 2008). The main part is consumed as tomato puree, paste, or sauce (Mirondo and Barringer 2015). Tomato culture is concerned by the agricultural use of fresh water for irrigation (Postel, Daily et al. 1996). Water resources are indeed under threatand the gap between water availability and demand is exacerbated by global climate changes (Afzal, Battilani et al. 2016). Processing tomato, an intensive production in terms of water use, is highly concerned with this issue (Rinaldi, Ventrella et al. 2007). The yield reduction depends on water deficit intensity and duration as well as on its timing during tomato development (Rinaldi, Ventrella et al. 2007; Patane and Cosentino 2010). 
Water availability is one of the main factor impacting plant growth and consequently harvestable yield (Boyer 1982; Tardieu, Granier et al. 2011; Katerji, Campi et al. 2013; Ripoll, Urban et al. 2014). WD reduces the weight of individual fruits more than the number of fruits per plant (Casa and Rouphael 2014). Because mild WD decreases fruit water accumulation more than dry mass accumulation, the decrease in yield may in fact turn out positive for processing. Indeed, tomato process includes a phase of dehydration/concentration, and reducing water content of raw material makes the process more efficient. Large variations in paste quality traits (color, consistency, soluble solid content, $\mathrm{pH}$ and titratable acidity) were found among cultivars (Garcia and Barrett 2006). High viscosity, fresh flavor and retention of natural color are important quality traits of ketchup and tomato puree (Chong, Simsek et al. 2009). Concerning viscosity, dehydration during processing has a major influence. However, relationships between dry matter content and viscosity on one hand, and between dry matter content and soluble solid content (SSC, in ${ }^{\circ} \mathrm{Brix}$ ) on the other hand, are well-known from manufacturers since puree price is based on ${ }^{\circ} \mathrm{Brix}$. However, SSC is not the only factor affecting rheology (Barrett, Garcia et al. 1998). Processing parameters such as breaking temperature and dynamic sieving modify the water soluble/insoluble solid content ratio, particle sizes and pectin state, which, in turn, affect the puree rheology (Sanchez, Valencia et al. 2002; Moelants, Cardinaels et al. 2014). Those physicochemical variables depend on the biological structures of fruit tissues and their reactivity to the process. For example, breaking temperature is currently used to modulate the consistency of tomato products: a high temperature treatment, immediately after fruit crushing (hot break, HB: $90^{\circ} \mathrm{C}$ ) produces much more viscous purees than cold break (CB) treatment, where fruits are first crushed and then macerated at moderate temperature $\left(70^{\circ} \mathrm{C}\right.$; Moelants et al., 2014). The quality of tomato puree is built throughout the food chain. Currently, in industry, the quality of processed fruits is assessed through the color and Brix index only, whereas other physical, structural and biochemical traits are overlooked. Insights into interactions between factors that drive fruit quality during the growing season and those that operate during processing must be more mastered, so in this work we investigated fruit quality in response to water supply and genotypes for the second year in a row, and we assessed their impact on puree quality obtained from $\mathrm{HB}$ and $\mathrm{CB}$ processes at the maturity to confirm data obtained in the previously season published by Vilas Boas et al, 2017.

\section{MATERIALS AND METHODS}

Four industry-type (determinate) cultivars of Solanum lycopersicum, namely "H1015," "H1311," "Miceno," and "Terradou" were used following the criteria of choice of the previous experiment in the year 2016 (Boas, Page et al. 2017). All seeds were germinated under standard glasshouse conditions $\left(25^{\circ} \mathrm{C}\right.$ day, $15^{\circ} \mathrm{C}$ night) near Avignon, France, in April 2017. Plant were transfer to field by the beginning of June.

Two blocks of 1,800 plants each (450 plants per cultivar) were designed in an

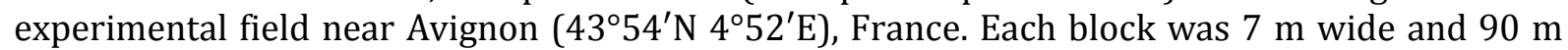
long and surrounded by border tomato plants. The four genotypes and the two irrigation regimes were randomly distributed within the two blocks. All plants were grown under conventional tomato management in France. Irrigation was supplied by a drip irrigation system. It was scheduled daily to compensate the evapotranspiration loss from tomato crop (ETP). ETP was determined daily using reference evapotranspiration estimated from the Penman-Monteith equation (Monteith 1965) and taking into account crop coefficient (Kc) and precipitations. Water was first supplied every day in order to fully fit $100 \%$ of ETP. Forty-five days after sowing, two levels of irrigation were applied: (1) water deficit (50\% replacement of ETP) and (2) wellwatered (control) to match $100 \%$ replacement of ETP. To mimic current production practices, irrigation was stopped two weeks before harvest. The soil water potential was recorded hourly using Watermark (Campbell Scientific, Antony, France) soil moisture sensors (six per water regime), which were installed at 25 and $50 \mathrm{~cm}$ depths.

\subsection{Plant and fresh fruit measurements}


During the WD treatment, from June to August 2017, the records showed reduced soil humidity at $25 \mathrm{~cm}$ depth when compared to the control. Control plants experienced higher soil water potentials than plants under WD at $25 \mathrm{~cm}$ depth. Under well-watered condition, $50 \%$ of the data (between the upper and the lower quartile) ranged from -38 to $-13 \mathrm{kPa}$, while under WD $50 \%$ of the data ranged from -57 to $-27 \mathrm{kPa}$. At $50 \mathrm{~cm}$ depth, soil water potentials remained similar between the two irrigation treatments.

\subsection{Fresh fruit quality}

Dry matter and soluble solid content (SSC) were measured at the harvest. The dry matter content was determined by weighting $3 \mathrm{~g}$ of fruit pericarp pieces before and after drying at $85^{\circ} \mathrm{C}$. The SSC was measured by refractometry with an ATAGO PR-1000 digital refractometer with automatic temperature compensation at $25^{\circ} \mathrm{C}$ and results were expressed in degree Brix, according to AOAC (2002) (AOAC 2002) after the fruits are mixed in a blender.

\subsection{Tomato processing and quality}

Purees from red ripe fruits were prepared by either hot break (HB) or cold break (CB) treatment according to a laboratory scaled method described by Page et al. (2012). Fruits were cut into large pieces (around $2 \mathrm{~cm}^{3}$ ), mixed altogether, and split into two identical batches of $400 \mathrm{~g}$ each. For HB, one batch was first heated until boiling temperature in a microwave oven ( $900 \mathrm{w}$, full power, $0.9 \mathrm{~s} \cdot \mathrm{g}^{-1}$ of tomato), then chopped for $30 \mathrm{~s}$ in a Waring ${ }^{\circledR}$ blender. For CB, the other batch was first chopped at room temperature for 30s in the same Waring ${ }^{\circledR}$ blender and then heated for the same duration and conditions than for HB. Both purees were then passed through a hand-held potato masher with a $2 \mathrm{~mm}$ grid to remove skins and seeds, stored into a $500 \mathrm{ml}$ glass jar with sealed lid, sterilized for $15 \mathrm{~min}$ at $100^{\circ} \mathrm{C}$ in a laboratory scaled autoclave, and stored at $4^{\circ} \mathrm{C}$ before analysis. The grinding step at room temperature in CB process allowed for the reaction of fruit intrinsic enzymes (especially polygalacturonase and pectin-methyl esterase) on cell walls, and therefore leads to lower consistency of purees compared to HB ones (Anthon et al., 2002). Consequently, the enzymatic potential of fruits was indirectly estimated as the difference in puree consistency between HB and CB processes, in our standardized conditions. The color of the purees was measured with a Minolta CR.400 using a specific cuvette for measurement of liquid or paste color and calibrated against a white background. Color results were expressed in the $\operatorname{CIE~} \mathrm{L}^{*} \mathrm{a}{ }^{*} \mathrm{~b}^{*}$ color space. Color coordinates were used to calculate the hue angle $\left(\mathrm{H}^{\circ}\right)$, which identifies the color at a $360^{\circ}$ angle (McGuire 1992). The dry matter content was determined by weighting around $3 \mathrm{~g}$ of fruit puree before and after drying for 3 days at $85^{\circ} \mathrm{C}$. The soluble solid content (SSC) was measured by refractometry with an ATAGO PR-1000 digital refractometer with automatic temperature compensation at $25^{\circ} \mathrm{C}$ and results were expressed in degree Brix, according to AOAC (2002). The pH was determinate using a ph meter. Rheological behavior of the puree was assessed through characteristic measurements: the viscosity was calculated from a steady state measurement performed on an Anton Paar MCR 301 viscosimeter (Graz, Austria), with a double ribbon impeller (with an inner radius of $11 \mathrm{~mm}$, a pitch of $45 \mathrm{~mm}$, a length of $45 \mathrm{~mm}$, and an outer stationary cup with an outer radius of 14.46 $\mathrm{mm})$. A flow curve was registered between 0.1 and $100 \mathrm{~s}-1,50$ points and $5 \mathrm{~s}$ per point. Flow properties were described by the Herschel-Bulkley model (Espinosa, To et al. 2011).

\subsection{Data analyses}

Data were analyzed using $\mathrm{R}$ statistical software (http://www.R-project.org). Physiological traits, data of yield, and quality traits were analyzed by analysis of variance (the agricolae R package and aov function; De Mendiburu, 2014). Heteroscedasticity and normality tests were performed before model evaluation. When the ANOVA F-test showed no significant difference in means between the blocks, data from block 1 and 2 were pooled. Multiple comparison of means was performed using the Least Significant Differences (LSD) test ( $\alpha=$ $0.05)$. When heteroscedasticity was detected, we used the Kruskal-Wallis non-parametric test followed by multiple comparisons of means through a t-student test on the ranks $(\alpha=0.05)$.

\section{RESULTS AND DISCUSSION}


Univariate ANOVAs were performed on plant and fruit traits to analyze the effects of WD, genotype, cooking, blocks and their interactions. Results were compared to those obtained in 2016 by Boas et al (2017).

\subsection{Fresh Fruits Biomass and Quality Affected by Water Deficit}

To the contrary of what was observed in the 2016 experiment, in 2017 the fresh fruit biomass decreased in production when the plants were exposed to water deficit (figure $1 \mathrm{~A}$ ). The WD treatment produced $-11 \%$ for "H1311", -30\% for "Miceno", $-24 \%$ for "Terradou" and $-34 \%$ for "H1015". However, analyzing dry weight yield, the results went to the same direction as observed in the experiment of 2016 with the WD slightly increasing the total dry fruit biomass for H1015 (+29\%) and H1311 (+11\%), but no differences were revealed for "Terradou" and "Miceno" (figure 1B). With this result, it can be stated that even with a decrease in the production of fresh biomass, which is expected when a water deficit is applied, the total dry biomass remained at least at the same level as the control plants.

Water deficit also slightly increased the fruit dry matter content (DMC) (Figure 2A) and fruit soluble solids content (SSC) (Figure 2B). These results are in agreement with previous works on the effects of moderate deficit irrigation on processing tomato (Boas, Page et al. 2017), and correspond to the objective of the industry consisting in saving energy for water evaporation by treating raw fruit with higher dry mater content. The increased of the fruit DMC was up to $+30 \%$ for "Miceno", $+29 \%$ for "H1015", $+24 \%$ for "Terradou" and $+22 \%$ for "H1311. It is important to note that there was an increase of approximately two points in the value of SSC in the year 2017, compared to the year 2016, in particular, H1311 closed a gap with Terradou, while it was 2 points lower in our previous study.It seems that H1311 is more sensitive to environmental factors than Terradou.

The increase in fruit dry matter content in response to WD is well-known (Ripoll et al., 2014). Ripoll et al. (2016)(Ripoll, Urban et al. 2016) have already underlined that beneficial effects of moderate WD on fruit sugar, acid and carotenoid contents, reported on a fresh weight basis, mainly results from a dehydration effect, which is confirmed by Boas et al (2017) and in this study. In addition, effects of WD on fruit DMC strongly depend on genotype and stress intensity (Ripoll et al., 2016). In our study, the WD applied from flowering to harvest did not modify the ranking of genotype in terms of DMC and SSC. The reduction of fresh fruit yield has been already obtain in industry type tomato, but, here we demonstrate that significant gain in tomato watering can be obtain without any loss of dry mater production per ha, if WD is monitored all along the fruit development (Stikic, Popovic et al. 2003; Patane and Cosentino 2010)

2.2 Genotype Controlled Puree Quality While WD Improved Rheological Properties

Tomatoes fruits were processed through CB and HB methods and puree quality was assessed based on puree viscosity, puree dry matter content (DMC), puree soluble solids contents (SSC) and color parameters $\left(\mathrm{H}^{\circ}\right)$. In all tests, no bloc effect was found, except for SSC and color. We further analyzed the interactions between genotype and irrigation treatment, and their effects on puree rheological properties (Figure 3). For viscosity, the genotype, irrigation and cooking effects were significant. Cultivar was the main effect, and especially "H1311" produced the most viscous purees in all situations (Figure 3A), as already obtained. Regarding the fruit composition, the difference of viscosity cannot be related to dry matter content of the fruits or soluble solid content, as minor difference of dry weight content was observe between H1311 and other cultivars, indicating that, other mechanisms governed viscosity changes in tomato purees. This result is consistent with result obtain for apple purees (Espinosa-Munoz, Symoneaux et al. 2012; Leverrier, Almeida et al. 2016) were particle structure and serum viscosity are pointed out as primary factors determining puree viscosity. As observed in the 2016 experiment, the WD applied in our experiment improved puree viscosity of all cultivars, despite no change in fruit composition (on a dry weight basis) and no correlation 
between fruit dry matter content and puree viscosity. WD led to significant higher viscosity of purees, presenting $+57 \%$ in "H1015", $+33 \%$ for "Terradou", $+10 \%$ at contains higher DMC as was fruit dry mater content (fig 4A). Interestedly only results between genotypes showed significantly differences for the differences of viscosity between HB and CB process (figure 3B), which leads to a different response to what was observed in the year 2016, where also the cooking processes affected the difference of viscosity, Here, to the contrary, the higher viscosity may be related to the higher dry mater content of fruit, as our experimental purees are not further concentrated after fruit chopping, heating and sieving.

We still propose that the effect of WD on puree rheology was driven by changes in pectin composition, and by changes in particle size and shape. Indeed, transcriptome analysis has revealed that plant response to drought includes differential cell wall synthesis and remodeling (Tenhaken 2015). The difference in rheology after HB and CB treatments is attributed to temperature effects on endogenous pectinolithic enzymes, namely polygalacturonase (PG) and pectin methyl-esterase (PME) involved in fruit softening (Anthon and Barrett 2002; Moelants, Cardinaels et al. 2014). The involvement of these enzymes has been confirmed by HB/CB processing of genetically modified tomatoes (Errington, Tucker et al. 1998), but the exact relationship between PG, PME and rheology remained partially obscure. Indeed $C B$ treatment leads to different biochemical and physical properties of water soluble pectins when compared to HB (Lin, Aizawa et al. 2005; Lin, Qin et al. 2005). The proportion of water insoluble solids is not significantly different between CB and HB purees (Sanchez et al., 2002), but particle size and shape are also impacted by the breaking temperature (Errington et al., 1998). It has been shown in other plant species, that pectin-degrading enzymes can be downregulated by water stress (Le Gall, Philippe et al. 2015). Thus, the activity of pectindegrading enzymes in response to $\mathrm{WD}$ should be analyzed in further details to disentangle the effect of pectinolithic enzymes from the effect of particles.

$\mathrm{PH}$ of purees showed high variability of values between cultivars. PH ranged from 4.28 ("Miceno") to 4.46 ("H1311"). PH was not influenced by WD for any of the cultivars (data not shown). However, when regarding the cooking processes we obtained a significant $\mathrm{pH}$ differences (from 0.2 to 0.4 more for HB compared to $\mathrm{CB}$ ). This result is consistent with previous result indicating that no significant effects on fruit biochemical composition were detected between WD and control. The higher pH of HB purees may be a problem especially for cultivar exhibiting $\mathrm{pH}$ close to the value of 4.5 , generally considered as a limit for the self-protection of acid-food (like tomato puree are) regarding microbiological contamination.

About the color parameters, Hue angle $\left(\mathrm{H}^{\circ}\right)$ values were significantly affected by genotype, cooking, irrigation and blocks. Despite the differences between the blocks, the behavior of the puree's colors paralleled in both, with purees from "H1311" fruits presented the lowest values of $\mathrm{H}^{\circ}$, and consistently with the higher content of lycopene of this cultivar. All H1311 are more red than the others, which was also verified in the experiment of the year 2016.

\section{CONCLUSION}

Results obtained in 2017 confirmed the results already presented in the year 2016 indicating that tomato fruit quality and processing ability are impacted by irrigation regime as well as genotype. The same variations between genotype, treatments and cooking process were observed showing fruits from a water stress with higher contents of dry matter, soluble solids and a higher viscosity. On the other hand, there is still no complete link between dry matter content and viscosity, and so, in perspective, we have to analyze other quality components (particle size, their distribution between large and small, serum viscosity) to understand what changes the textures and how crop conditions influence these parameters. 


\section{ACKNOWLEDGMENTS}

CAPES and the Brazilian Ministry of Education; Société Nationale Interprofessionnelle de la Tomate (SONITO) and the Structure Fédérative de Recherche Tersys

\section{REFERENCES}

Afzal, M., A. Battilani, et al. (2016). "Improving water resources management using different irrigation strategies and water qualities: Field and modelling study." Agricultural Water Management 176: 40-54.

Anthon, G. E. and D. M. Barrett (2002). "Kinetic parameters for the thermal inactivation of quality-related enzymes in carrots and potatoes." Journal of Agricultural and Food Chemistry 50(14): 4119-4125.

AOAC (2002). Official Methods of Analysis of AOAC International, 17th Edn. Gaithersburg, AOAC International.

Barrett, D. M., E. Garcia, et al. (1998). "Textural modification of processing tomatoes." Critical Reviews in Food Science and Nutrition 38(3): 173-258.

Boas, A., D. Page, et al. (2017). "Combined Effects of Irrigation Regime, Genotype, and Harvest Stage Determine Tomato Fruit Quality and Aptitude for Processing into Puree." Frontiers in Plant Science 8.

Boyer, J. S. (1982). " Plant productivity and environment." Science 218: 443-448.

Casa, R. and Y. Rouphael (2014). "Effects of partial root-zone drying irrigation on yield, fruit quality, and water-use efficiency in processing tomato." Journal of Horticultural Science \& Biotechnology 89(4): 389-396.

Chong, H. H., S. Simsek, et al. (2009). "Analysis of cell-wall pectin from hot and cold break tomato preparations." Food Research International 42(7): 770-772.

Dorais, M., D. L. Ehret, et al. (2008). "Tomato (Solanum lycopersicum) health components: from the seed to the consumer." Phytochem. Rev. 7: 231-250.

Errington, N., G. A. Tucker, et al. (1998). "Effect of genetic down-regulation of polygalacturonase and pectin esterase activity on rheology and composition of tomato juice." Journal of the Science of Food and Agriculture 76(4): 515519.

Espinosa-Munoz, L., R. Symoneaux, et al. (2012). "The significance of structural properties for the development of innovative apple puree textures." Lwt-Food Science and Technology 49(2): 221-228.

Espinosa, L., N. To, et al. (2011). Effect of processing on rheological, structural and sensory properties of apple puree. 11 th International Congress on Engineering and Food. G. Saravacos, P. Taoukis, M. Krokidaet al. Amsterdam, Elsevier Science Bv. 1: 513-520.

Garcia, E. and D. M. Barrett (2006). "Evaluation of processing tomatoes from two consecutive growing seasons: Quality attributes, peelability and yield." Journal of Food Processing and Preservation 30(1): 20-36.

Katerji, N., P. Campi, et al. (2013). "Productivity, evapotranspiration, and water use efficiency of corn and tomato crops simulated by AquaCrop under contrasting water stress conditions in the Mediterranean region." Agricultural Water Management 130: 14-26.

Le Gall, H., F. Philippe, et al. (2015). "Cell wall metabolism in response to abiotic stress." Plants 4: 112-166.

Leverrier, C., G. Almeida, et al. (2016). "Influence of Particle Size and Concentration on Rheological Behaviour of Reconstituted Apple Purees." Food Biophysics 11(3): 235-247.

Lin, H. J., K. Aizawa, et al. (2005). "Physical properties of water-soluble pectins in hot- and cold-break tomato pastes." Food Chemistry 93(3): 403-408.

Lin, H. J., X. M. Qin, et al. (2005). "Chemical properties of water-soluble pectins in hot- and cold-break tomato pastes." Food Chemistry 93(3): 409-415.

McGuire, R. G. (1992). "REPORTING OF OBJECTIVE COLOR MEASUREMENTS." Hortscience 27(12): 1254-1255.

Mirondo, R. and S. Barringer (2015). "Improvement of Flavor and Viscosity in Hot and Cold Break Tomato Juice and Sauce by Peel Removal." Journal of Food Science 80(1): S171-S179.

Moelants, K. R. N., R. Cardinaels, et al. (2014). "A Review on the Relationships between Processing, Food Structure, and Rheological Properties of Plant-Tissue-Based Food Suspensions." Comprehensive Reviews in Food Science and Food Safety 13(3): 241-260.

Monteith, J. L. (1965). "Evaporation and environment." Symp. Soc. Exp. Biol. 19: 205 - 234.

Patane, C. and S. L. Cosentino (2010). "Effects of soil water deficit on yield and quality of processing tomato under a Mediterranean climate." Agricultural Water Management 97(1): 131-138.

Postel, S. L., G. C. Daily, et al. (1996). "Human appropriation of renewable fresh water." Science 271(5250): 785-788.

Rinaldi, M., D. Ventrella, et al. (2007). "Comparison of nitrogen and irrigation strategies in tomato using CROPGRO model. A case study from Southern Italy." Agricultural Water Management 87(1): 91-105.

Ripoll, J., L. Urban, et al. (2016). "Water deficit effects on tomato quality depend on fruit developmental stage and genotype." Journal of Plant Physiology 190: 26-35.

Ripoll, J., L. Urban, et al. (2014). "Water shortage and quality of fleshy fruits-making the most of the unavoidable." Journal of Experimental Botany 65(15): 4097-4117.

Sanchez, M. C., C. Valencia, et al. (2002). "Influence of processing on the rheological properties of tomato paste." Journal of the Science of Food and Agriculture 82(9): 990-997.

Stikic, R., S. Popovic, et al. (2003). "Partial root drying (PRD): a new technique for growing plants that saves water and improves the quality of fruit." Bulg. J. Plant Physiol. 29: 164-171. 


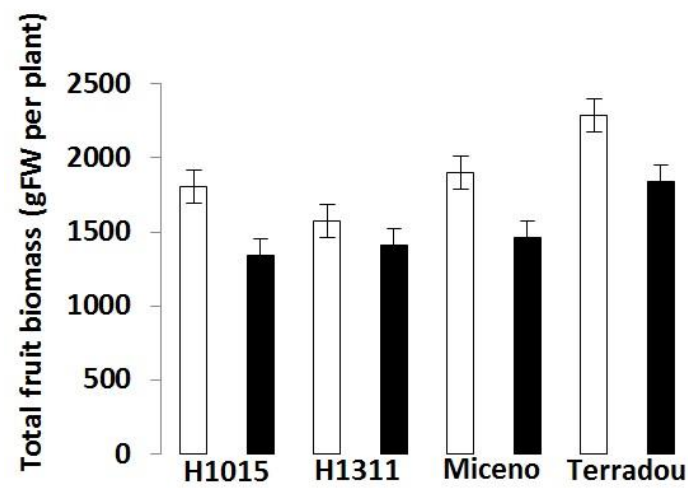

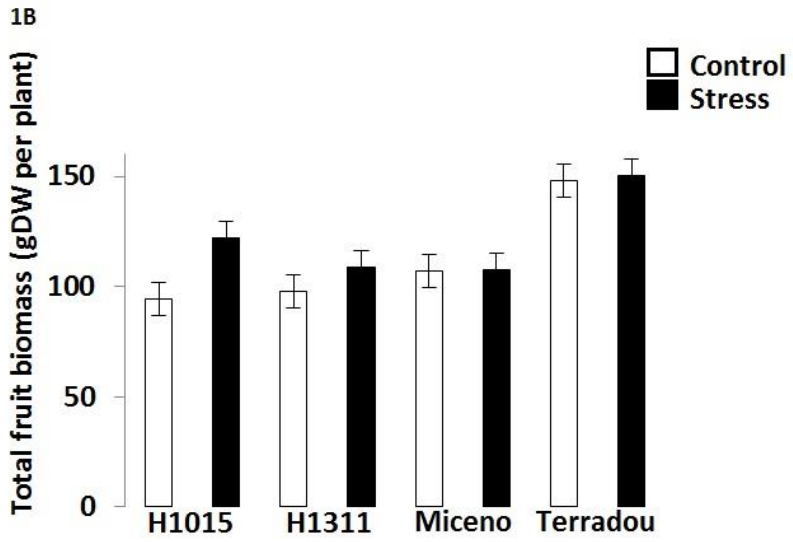

Figure 1. Impact of water deficit and cultivar on fresh (A) and dry (B) yield expressed as total fruit biomass (g) per plant. Note that the color code blue is for well-watered plants and gray for plants under water deficit

Figure 2. Changes in yield-related traits determined for the four cultivars conditions and under the two water regimes (control in white and water deficit in black): individual fruit fresh weight (FW) (A) and dry matter content of fruit pericarp collected at 55 DAA

3 A
2B

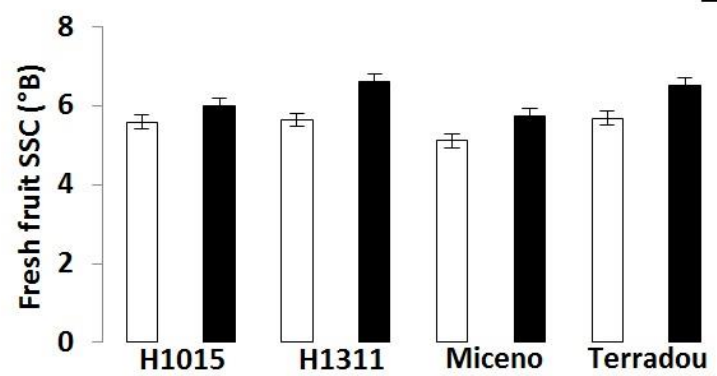

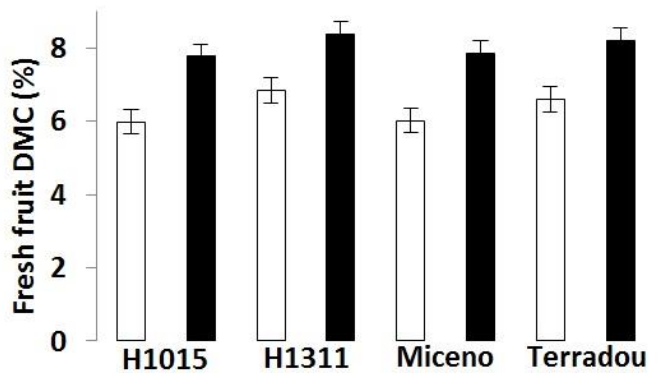

$3 B$
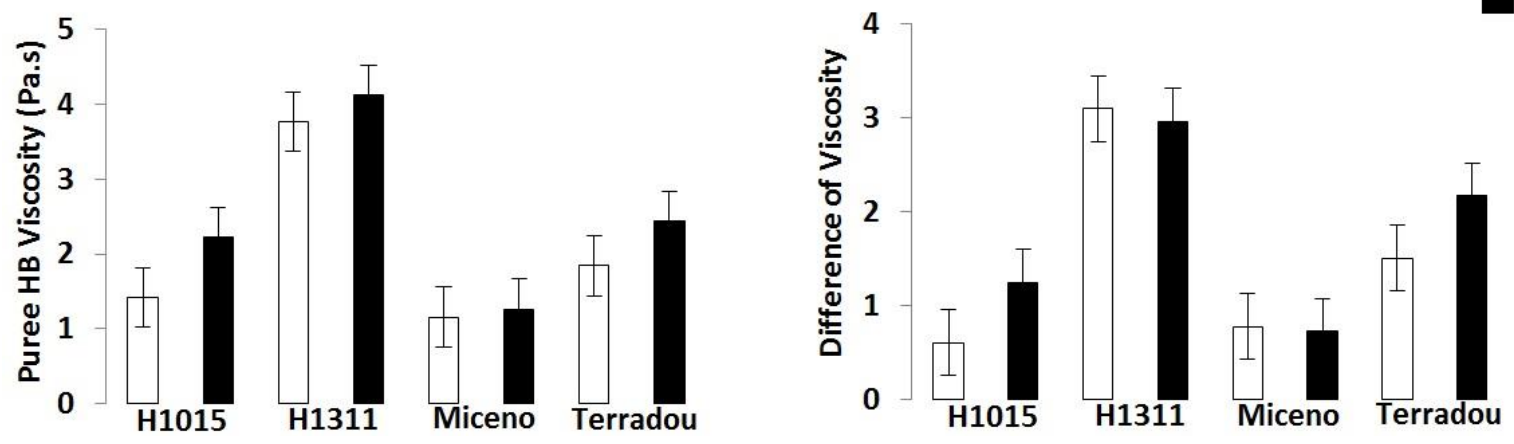

Figure 3. Impact of water deficit and genotype on the rheology and changes in "Hot Break" puree (A). Difference of consistency between "Cold break" and "Hot break" purees obtained from fruits collected at harvest (B). 
$4 \mathrm{~A}$

334

335

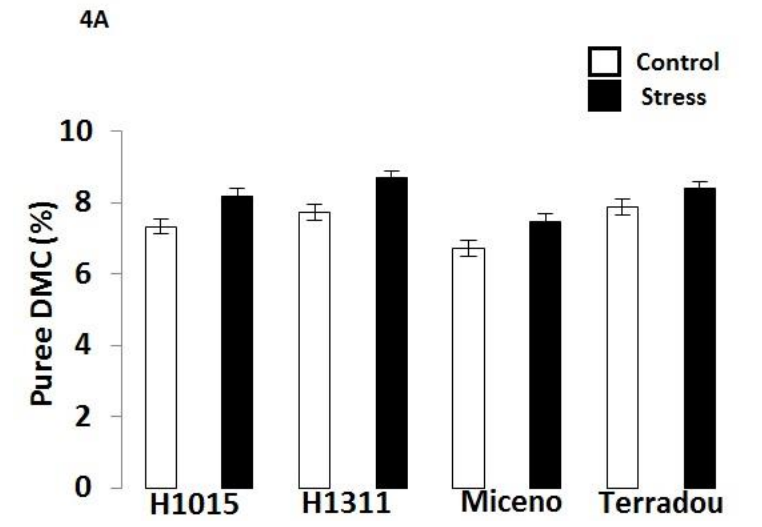

$4 B$

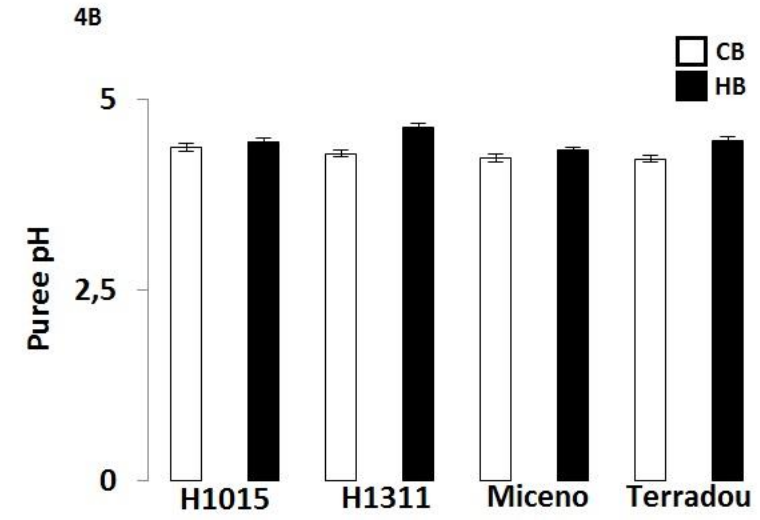

Figure 4. Impact of water deficit and genotype on the puree dry matter content (DMC) (A). Difference of pH between Cold break and Hot break purees obtained from fruits collected at harvest (B). 